\title{
Canadian experts seek pediatric formulary
}

$\mathrm{C}$ anada is lagging behind a worldwide move in the last decade to establish consistent, evidence-based guidelines for medication use in children. Since 2005, for example, national pediatric "formularies" have been developed in the United Kingdom, the Netherlands and New Zealand.

Health Canada commissioned an analysis of the state of pediatric prescribing from the Council of Canadian Academies, a nonprofit that provides independent, science-based assessments to inform public policy. The 2014 report concluded that "medicines must be studied in children and formulated for children" and recommended that "a pan-Canadian prescribing resource, such as a formulary, could provide clear guidance to prescribers with standards for administering medications to children."

But since the report was released, little has happened.

So in September, researchers from Child Health Evaluative Sciences at The Hospital for Sick Children in Toronto organized a one-day symposium to examine pediatric formularies in other countries and to restart the discussion of harmonized care for Canadian kids.

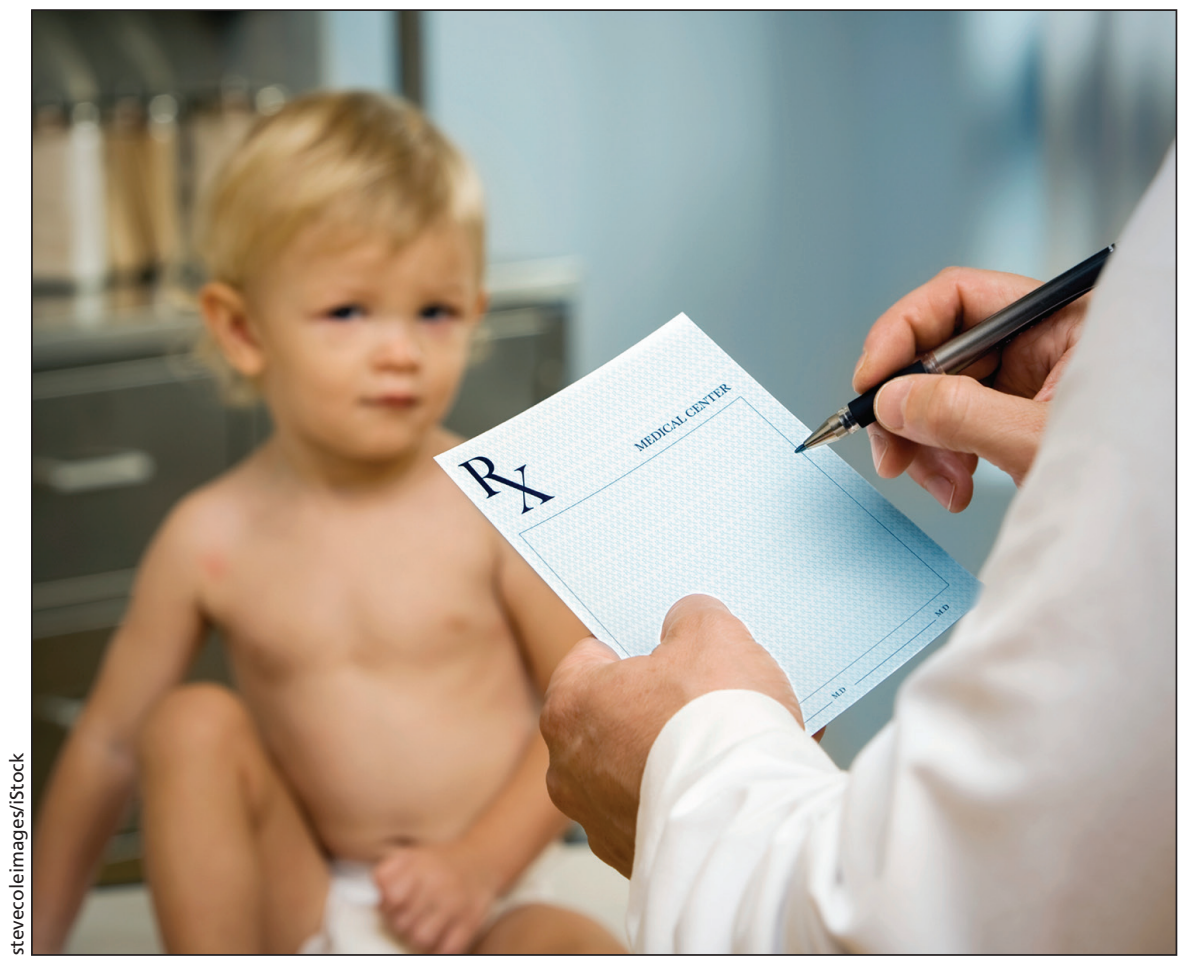

The UK, Netherlands and New Zealand have had national pediatric formularies since 2005.

likely be under $\$ 500000$, he said, but few funding bodies will commit to long-term financing for even such a relatively small amount.

The UK formulary is based on a commercial model that 't Jong would not like to see replicated here because it

\section{Annual costs would likely be under $\$ 500000$, but few funding bodies will commit to long- term financing for even such a small amount.}

"This is a no-brainer step for us to take," Dr. Geert 't Jong, assistant professor of pediatrics and pharmacology at the University of Manitoba, told attendees at the Recent Advances in Pediatric Drug Prescribing conference on Sept. 9.

The sticking point seems to be financing, 't Jong said in an interview. Establishing a formulary — a term the researchers used to mean a drug information handbook - requires not only compiling current information, but also maintaining and updating it in perpetuity.

The ongoing annual cost would should be free to all clinicians. The New Zealand effort is financed by its health ministry, and the Dutch formulary is paid for in part by dues paid to the national pediatric society and in part by the government.

A recent opinion piece on the subject in the Winnipeg Free Press, by Drs. Terry Klassen, head of pediatrics and child health at the University of Manitoba, and Martin Offringa, professor of pediatrics at the University of Toronto (and co-organizer of the symposium), put the case succinctly. "It's time Health Canada made progress on the recom- mendations of a report they, themselves, commissioned — and for the federal government to set the course."

Leaders from Canadian children's hospitals, headed by 't Jong, Offringa, Klassen and Dr. Thierry Lacaze, head of neonatology at the Children's Hospital of Eastern Ontario, are jointly preparing a comprehensive proposal for a childhealth drug research network for submission to Health Canada, 't Jong said.

International pharmaceutical companies are now promoting a plan to develop a global pediatric clinical trials network involving national networks of the best children's hospitals in more than 20 countries.

"Can we really afford not to be part of this global development and miss having our national infrastructure organized?" Klassen and Offringa asked in their editorial.

Several participants from the Toronto symposium plan to consult with other interested parties and investigate funding possibilities to start work on developing a Canadian formulary, 't Jong said. - Terry Murray, Toronto, Ont.

CMAJ 2016. DOI:10.1503/cmaj.109-5184 